\title{
Hyphae Formation of Candida albicans Is Regulated by Polyamines
}

\author{
Yukihiro Ueno, Makoto Fukumatsu, Ayako Ogasanara, Toshihiko Watanabe, Takeshi Mikami, and \\ Tatsuzi Matsumoto* \\ Department of Microbiology, Tohoku Pharmaceutical University; Sendai 981-8558, Japan. \\ Received December 22, 2003; accepted March 17, 2004
}

\begin{abstract}
Candida albicans generally grows in hyphae form in RPMI1640 medium. However, addition of 1,4-diamino2-butanone (DAB), a competitive inhibitor of ornithine decarboxylase, decreased the amount of polyamines in $C$. albicans, and induced the proliferation of the $C$. albicans yeast form. The expression of $C Y R 1$ mRNA was significantly inhibited by the addition of DAB compared with that of the control. The amount of intracellular cAMP was also decreased by the addition of DAB. A specific adenylate cyclase inhibitor, cis- $N$-[2-phenylcyclopentyl]azacyclotridec-1-en-2-amine (MDL-12,330A) promoted the growth of the yeast form. These results indicated that polyamines exist upstream of the adenylate cyclase-cAMP signal pathway and regulate the transformation of $C$. albicans.
\end{abstract}

Key words Candida albicans; 1,4-diamino-2-butanone (DAB); polyamine; cis- $N$-[2-phenylcyclopentyl]-azacyclotridec-1-en-2amine (MDL-12,330A); cAMP ornithine decarboxylase

Candida albicans are opportunistic fungi which generally exist in the oral cavity, skin, vagina and intestinal organs, ${ }^{1,2}$ and are dimorphic fungi which undergo a transition from the yeast form to the hyphal form depending on the growth conditions. ${ }^{3,4)}$ They grow in yeast form at membranes and the surface of the skin, but in hyphae form at the deep-seated mycosis.

Temperature, $\mathrm{pH}$ and $\mathrm{Ca}^{2+}$ are known as external factors of the transformation. ${ }^{5-7)}$ The hyphae transformation is induced by the activation of the MAP kinase and cAMP pathways, which are controlled by RAS protein. ${ }^{8,9)}$

Polyamines are synthesized from ornithine by ornithine decarboxylase (ODC) and known as inducers of adenylate cyclase. ${ }^{10}$

In this report, we discovered that polyamines participated in the transformation of C. albicans, and the activation of adenylate cyclase was related to the transformation.

\section{MATERIALS AND METHODS}

Organism and Growth Conditions C. albicans NIH A207 strain was routinely grown in Sabouraud's medium (peptone $10 \mathrm{~g}$, glucose $20 \mathrm{~g}$ and yeast extract $5 \mathrm{~g}$, per liter). To induce hyphae formation, the cells were grown in RPMI1640 medium at $37^{\circ} \mathrm{C}$.

Reagents 1,4-Diamino-2-butanone (DAB) was purchased from Aldrich Chemical Co. (Mo, U.S.A.). cis- $N$ [2-Phenylcyclopentyl]-azacyclotridec-1-en-2-amine (MDL12,330A) was purchased from Sigma Chemical Co. (Mo, U.S.A.).

The Amount of Polyamines in C. albicans C. albicans cells $\left(1 \times 10^{5}\right.$ cells $/ \mathrm{ml}$ in RPMI1640) were incubated with $\operatorname{DAB}(0,960 \mathrm{~mm})$ in $5 \% \mathrm{CO}_{2}$ at $37^{\circ} \mathrm{C}$ for 1 and $3 \mathrm{~h}$. Cells were washed twice with sterile water and disrupted with a Mini-Beadbeater (diameter of glass beads, $0.3 \mathrm{~mm}$, Central Scientific Commerce, Inc.). Total proteins in the supernatant were analyzed at $280 \mathrm{~nm}$ and polyamines levels were determined using a Labosearch polyamine auto (A and T Corp.).

Yeast Induction of $C$. albicans by Polyamine Synthesis Inhibitor C. albicans cells were adjusted to $1 \times 10^{5}$ cells $/ \mathrm{ml}$ in RPMI1640. DAB $(0,30,60,120,240,480,960 \mathrm{~mm})$ was added and incubated in $5 \% \mathrm{CO}_{2}$ at $37^{\circ} \mathrm{C}$ for $3 \mathrm{~h}$. The ratio of hyphae cells was counted microscopically.

Reverse Transcription-Polymerase Chain Reaction (RT-PCR) Gene arrangement participated in the hyphae formation of C. albicans referenced using the Entrez System of the National Center for Biotechnology Information (U.S.A.). PCR primers were designed using the Search Launcher in the Human Genome Sequencing Center (U.S.A.). C. albicans cells $\left(1 \times 10^{5}\right.$ cells $/ \mathrm{ml}$ in RPMI1640) were incubated with $\mathrm{DAB}(0,960 \mathrm{~mm})$ in $5 \% \mathrm{CO}_{2}$ at $37^{\circ} \mathrm{C}$ for $3 \mathrm{~h}$. The cells were washed twice with sterile water. The cDNA library of the cells was synthesized with a Cells-tocDNA kit (Ambion Inc., U.S.A.). PCR reaction was conducted with a KOD-plus kit (Toyobo Co., Ltd.). Primers used in this assay are shown in Table 1. PCR products were analyzed using an Agilent 2100 Bioanalyzer (Agilent Technologies). The result was shown as a relative expression of mRNA compared with that of $A C T 1$ (actin) as described by McCreach's method. ${ }^{11}$

cAMP Concentration in $C$. albicans $\quad C$. albicans cells $\left(1 \times 10^{5}\right.$ cells $/ \mathrm{ml}$ in RPMI1640) were incubated with DAB $(0$, $960 \mathrm{~mm}$ ) in $5 \% \mathrm{CO}_{2}$ at $37^{\circ} \mathrm{C}$ for $3 \mathrm{~h}$. Cells were washed twice with sterile water and disrupted with a Mini-Beadbeater. Total proteins in the supernatant were analyzed at 280 $\mathrm{nm}$ and cAMP levels were determined using an EIA system cAMP immunoassay (Amersham Pharmacia Biotech., U.S.A.).

Table 1. DNA Primer Sequences

\begin{tabular}{ll}
\hline \hline \multicolumn{1}{c}{ Primer } & \multicolumn{1}{c}{ Sequence $\left(5^{\prime} \rightarrow 3^{\prime}\right)$} \\
\hline$A C T 1$ (sense) & ACTCACGTTGTTCGAATTTACGCT \\
$A C T 1$ (antisense) & ACCACCAGACATAACAATGTTACCG \\
$C Y R 1$ (sense) & GACAATGACGCAAATTTATCGG \\
$C Y R 1$ (antisense) & GAAAAACATGATCCAACCAATCG \\
$A L S 1$ (sense) & ACATTAACATGTACTGTGAACGACGC \\
$A L S 1$ (antisense) & AACTAAATGATTCAGATGAAACGGAT \\
$A L S 3$ (sense) & GATTGAATGATTGGAATTATCCGGT \\
$A L S 3$ (antisense) & TTTCAATTGGTCTTAGTTTGTCGCG \\
$A L S 8$ (sense) & GTATGAATGATTGGAATTACCGGT \\
$A L S 8$ (antisense) & TTTCAATTGTCTTAGTTTGTCGCG \\
\hline
\end{tabular}


Yeast Induction of $\boldsymbol{C}$. albicans by Adenylate Cyclase Inhibitor C. albicans cells were adjusted to $1 \times 10^{5}$ cells $/ \mathrm{ml}$ in RPMI1640. MDL-12,330A $(0,3,6,12,25,50 \mu \mathrm{g} / \mathrm{ml})$ was added and incubated in $5 \% \mathrm{CO}_{2}$ at $37^{\circ} \mathrm{C}$ for $3 \mathrm{~h}$. The ratio of hyphae cells was counted microscopically.

Statistical Analysis Values were shown as means \pm S.E., and statistical analysis of these data was performed using the Student's $t$-test. A $p<0.05$ was considered significant.

\section{RESULTS}

The Amount of Polyamines in C. albicans Stimulated by Polyamine Synthesis Inhibitor, DAB Because polyamines are produced from ornithine by ornithine decarboxylase, we measured the amount of intracellular polyamines to confirm the decline of ornithine decarboxylase activity in C. albicans by DAB. As shown in Fig. 1, polyamines levels were significantly decreased compared with that of the control.

Effect of Polyamine Synthesis Inhibitor on Transformation of $C$. albicans DAB was added to RPMI1640, and the hyphae ratio of $C$. albicans was measured. As shown in Fig. 2 , the hyphae formation was significantly inhibited by DAB. These results indicated that polyamines are related to the hyphae formation.

Expression of CYR1 mRNA in C. albicans Treated with Polyamine Synthesis Inhibitor As polyamine promotes the induction of adenylate cyclase in mammalian cells, we measured the expression of CYRI (adenylate cyclase in $C$. albicans) mRNA using the RT-PCR method. The expression of CYR 1 mRNA was inhibited significantly by the addition of DAB (Fig. 3), indicating that polyamine is related to the induction of adenylate cyclase in C. albicans.

cAMP Concentration in $C$. albicans Treated by Polyamine Synthesis Inhibitor To confirm the decline of adenylate cyclase activity in $C$. albicans, we measured the amount of intracellular cAMP because cAMP is produced from ATP by adenylate cyclase. The amount of cAMP treated with $\mathrm{DAB}$ was $234.6 \pm 13.7 \mathrm{fmol} / \mathrm{mg}$ of protein, which was significantly decreased compared with that of the control $(1799.3 \pm 244.1 \mathrm{fmol} / \mathrm{mg}$ of protein, $p<0.001)$.

Expression of mRNA Related to the Hyphal Formation in $C$. albicans Treated with Polyamine Synthesis Inhibitor The cAMP signal pathway regulates the expression of several proteins related to hyphae formation (ALS1, ALS3, ALS8). So, we measured these expressions by the RT-PCR method. As shown in Fig. 3, the relative expressions of these mRNAs were significantly inhibited by DAB.

Effect of Adenylate Cyclase Inhibitor on Transformation of $\boldsymbol{C}$. albicans To confirm the relationship between adenylate cyclase and the transformation, we measured the effect of specific adenylate cyclase inhibitor, MDL12,330A. ${ }^{8}$ As shown in Fig. 4, MDL-12,330A inhibited the hyphae formation of $C$. albicans. This result indicated that adenylate cyclase controls the transformation of $C$. albicans.

\section{DISCUSSION}

C. albicans are dimorphic fungi, ${ }^{3,4)}$ and the pathogenicity of hyphal cells is stronger than that of yeast cells at the infected site. ${ }^{12-14)}$

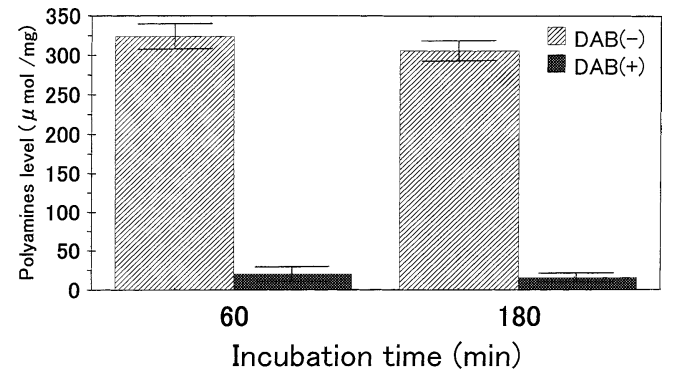

Fig. 1. The Amount of Polyamines in C. albicans Stimulated by DAB

Polyamines levels in C. albicans cultured with DAB were measured at the indicated times as described in Materials and Methods.

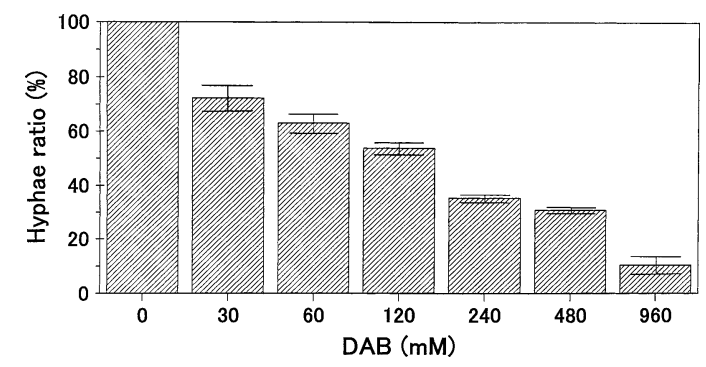

Fig. 2. Effect of DAB on Yeast to Hyphal Transformation of C. albicans

C. albicans $\left(1 \times 10^{5}\right.$ cells $/ \mathrm{ml}$ in RPMI1640) were incubated with DAB $(0,30,60$, $120,240,480,960 \mathrm{~mm})$ in $5 \% \mathrm{CO}_{2}$ at $37^{\circ} \mathrm{C}$ for $3 \mathrm{~h}$. After the incubation, the ratio of hyphae cells was measured.

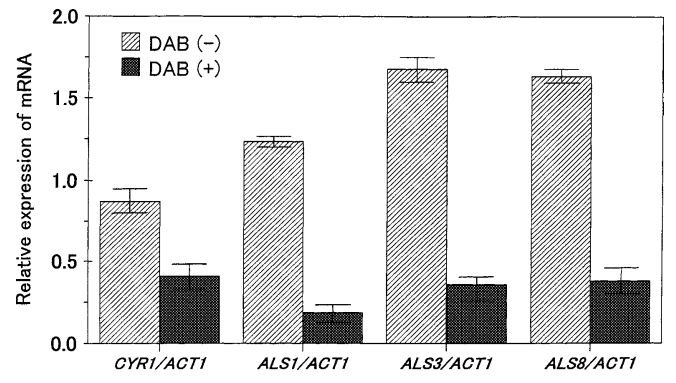

Fig. 3. Relative Expression of mRNAs in C. albicans Treated with DAB C. albicans $\left(1 \times 10^{5}\right.$ cells $/ \mathrm{ml}$ in RPMI1640) were incubated with DAB $(0,960 \mathrm{~mm})$ in $5 \% \mathrm{CO}_{2}$ at $37^{\circ} \mathrm{C}$ for $3 \mathrm{~h}$. After the incubation, the relative expressions of mRNAs were measured as described in Materials and Methods.

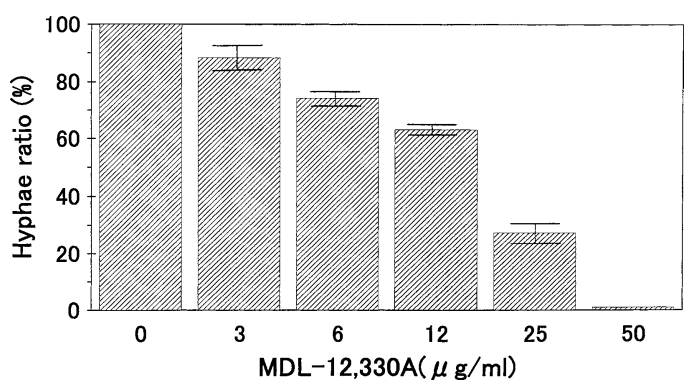

Fig. 4. Effect of MDL-12,330A on the Yeast-to-Hyphae Transformation of C. albicans

C. albicans $\left(1 \times 10^{5}\right.$ cells $/ \mathrm{ml}$ in RPMI1640) were incubated with MDL-12,330A (0, 3, $6,12,25,50 \mu \mathrm{g} / \mathrm{ml})$ in $5 \% \mathrm{CO}_{2}$ at $37^{\circ} \mathrm{C}$ for $3 \mathrm{~h}$. After the incubation, the ratio of hyphae cells was measured.

The cAMP signal pathway is a regulation system of the transformation. Herrero et. al. reported that the polyamine level in C. albicans affect the transformation. ${ }^{15)}$ However, the 


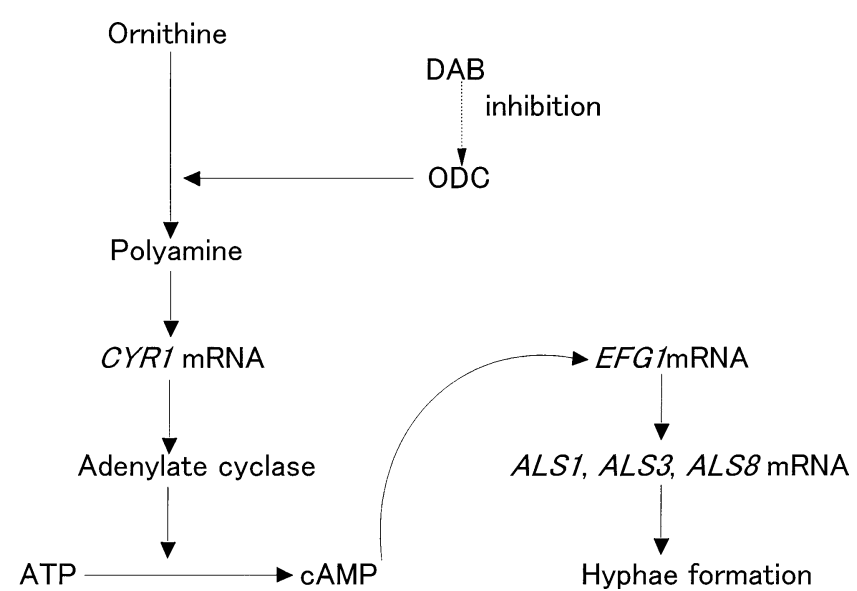

Fig. 5. Tentative Interaction of Polyamine to Adenylate Cyclase-cAMP Signal Pathway

relationship of polyamines and cAMP pathway is unclear. In this study, we demonstrated the role of polyamines in the transformation.

Hyphae cells were induced in RPMI1640, which includes essential factors for inducing hyphae cells, such as biotin, calcium and several amino acids. ${ }^{16)}$ To determine the correlation of polyamines to the transformation, we measured the effect of DAB on C. albicans. As shown in Figs. 1 and 2, the production of polyamines and hyphae formation in C. albicans were inhibited by DAB. These results indicated that polyamines play an important role in inducing hyphae cells.

As polyamines are adenylate cyclase inducers in mammalian cells, ${ }^{17-19)}$ so we expected that polyamines had similar effects in $C$. albicans. We measured the expression of adenylate cyclase $(C Y R 1)$ mRNA in $C$. albicans treated with DAB. The expression of CYRI cultured in RPMI1640 was significantly decreased by DAB (Fig. 3), indicating that polyamines induce adenylate cyclase in $C$. albicans. Moreover, we confirmed the activity of adenylate cyclase in C. albicans treated with DAB. The activity was shown as the amount of intracellular cAMP because cAMP is synthesized by adenylate cyclase. The amount of cAMP was also decreased by $\mathrm{DAB}$ as described in the results, indicating that polyamine acted as an adenylate cyclase inducer in $C$. albicans.

ALS1, ALS3 and ALS8 are related to hyphae formation, and are regulated by the cAMP signal pathway. ${ }^{20)}$ If polyamines control the pathway, the expression of these proteins may be inhibited by DAB. The relative expressions of the mRNAs cultured with DAB were significantly decreased compared with that of the control (Fig. 3).

To confirm that adenylate cyclase is a key substance in the transformation, we examined the effect of MDL-12,330A on C. albicans. MDL-12,330A inhibited hyphae formation (Fig. 4 ), indicating that adenylate cyclase-cAMP is a principal pathway of the transformation.

As shown in Fig. 5, we conclude that polyamines exist upstream of the adenylate cyclase-cAMP signal pathway and regulate the transformation of $C$. albicans.

\section{REFERENCES}

1) Orejas R. D., Moleo G., Garcia F. N., Pla J., Nombela C., Perez M. S., Infect. Immun., 65, 833-837 (1997).

2) Domer J. E., Human L. G., Andersen G. B., Rudbach J. A., Asherson G. L., Infect. Immun., 61, 2122-2130 (1993).

3) Gow N. A. R., Robbins P. W., Lester J. W., Brown A. J. P., Fonzi W. A., Chapman T., Kinsman O. S., Proc. Natl. Acad. Sci. U.S.A., 91, 62166220 (1994).

4) Swoboda R. K., Bertram G., Colthurst D. R., Tuite M. F., Gow N. A. R., Gooday G. W., Brown A. J. P., Microbiology, 140, 2611-2616 (1994).

5) Maneu V., Roig P., Gozalbo D., Res. Microbiol., 151, 739-746 (2000).

6) Porta A., Ramon A. M., Fonzi W. A., J. Bacteriol., 181, 7516-7523 (1999).

7) Holmes A. R., Cannon R. D., Shepherd M. G., FEMS Microbiology Lett., 77, 187-194 (1991).

8) Jain P., Akula I., Edlind T., Antimicrob. Agents Chemother, 47, 3195-3201 (2003).

9) Leberer E., Harcus D., Dignard D., Johnson L., Ushinsky S., Thomas D. Y., Schroppel K., Mol. Microbiol., 42, 673-687 (2001).

10) Lopez M. C., Garcia S., Ruiz-Herrera J., Dominguez A., Curr. Genet., 32, 108-114 (1997).

11) Brise C. E., Irwin M. Y., Fonzi W. A., Sypherd P. S., Infect. Immun., 61, 3648-3655 (1993).

12) Casanova M., Lopez-Ribot J. L., Martinez J. P., Sentandreu R., Infect. Immun., 60, 4898-4906 (1992).

13) Sherwood J., Gow N. A. R., Gooday D. W., Marshall D., J. Med. Vet. Mycol., 30, 461-469 (1992).

14) Cutler J. E., Annu. Rev. Microbiol., 45, 187-218 (1991).

15) Herrero A. B., Lopez M. C., Garcia S., Schmidt A., Spaltmann F., Ruiz-Herrera J., Dominguez A., Infect. Immun., 67, 4870-4878 (1999).

16) Manns J. M., Mosser D. M., Buckley H. R., Infect. Immun., 62, 5154-5156 (1994).

17) Mutafova-Yambolieva V. N., Smyth L., Bobalova J., Cardiovasc. Res., 57, 217-224 (2003).

18) Yeung S. M., Shoshani I., Stubner D., Johnson R. A., Arch. Biochem. Biophys., 271, 332-345 (1989).

19) Nilsson B. O., Rosengren E., Experientia, 49, 881-884 (1993).

20) Fu Y., Ibrahim A. S., Sheppard D. C., Chen Y. C., French S. W., Cutler J. E., Filler S. D., Edwards J. E., Jr., Mol. Microbiol., 44, 61-72 (2002). 